\title{
Thiosugars. XVI.1) Synthesis of Cellobiose Derivatives having Sulfur Atom in the Reducing Moiety
}

\author{
Setsuzo Tejima and Yoshimitsu Okamori \\ Faculty of Pharmaceutical Sciences, Nagoya City University2)
}

(Received May 4, 1972)

\begin{abstract}
A facile synthesis of cellobiosan hexaacetate (II) was described. Zemplén degradation of II, followed by the Koenigs-Knorr reaction was shown to yield $1,2,3,2^{\prime}, 3^{\prime}, 4^{\prime}, 6^{\prime}$-hepta-Oacetyl- $\beta$-cellobiose (III) in $45 \%$ yield. Crystalline 6 -methylsulfonate (IV), $p$-tolylsulfonate (V), and 6-deoxy-6-iodo acetate (VI) were synthesized. Starting from IV, via the crystalline ethylxanthate (VIII), 1,6-anhydro-6-thio- $\beta$-cellobiose (6-thiocellobiosan) (XIII) and the fully acetate (XII) were synthesized.

Five fully acetylated cellobiose derivatives (VII, IX, 'X, XI, and XIV) having sulfur atom at $\mathrm{C}_{1}, \mathrm{C}_{6}$, or both of the positions were also synthesized starting from octaacetyl- $\beta$-cellobiose, IV, or XII.
\end{abstract}

A number of new thio sugars have been synthesized in recent years, often for biological interest. Little work, however, has been done on reducing disaccharides having sulfur atom, except for thioglycosides. Namely, Dutton and Slessor ${ }^{3)}$ have reported on the synthesis of $6^{\prime}$-deoxy-6'-mercapto-maltose in their paper on synthesis of $6^{\prime}$-substituted maltoses which may be the sole work introducing a mercapto group other than the anomeric carbon in reducing disaccharides.

On the one hand, specifically substituted disaccharides are important as substrates in studies on the action of carbohydrases. The information gained in such specificity studies may be useful when applied to the action of these enzymes on oligo- and poly-saccharides. Nevertheless, little work has been done on the chemical substitution of reducing disaccharides as compared with that of monosaccharides. On maltose series, Sleeter and Sinclair ${ }^{4}$ have done on the substitution of methyl $\beta$-maltoside, and recently, a series of papers has been reported on that of phenyl $\alpha$-maltoside and the substrate specificity of. Taka-amylase A by Matsushima, et al.5)

In 1971, Tejima ${ }^{6}$ ) has prepared 1,6-anhydro-6-thio- $\beta$-lactose (6-thiolactosan) starting from lactosan hexaacetate via 1,2,3,2, $3^{\prime}, 4^{\prime}, 6^{\prime}$-hepta-O-acetyl- $\beta$-lactose. The prepared lactosan and 6-thiolactosan have been utilized by Sato and Yamashina ${ }^{7)}$ as substrates for characterization of $\beta$-galactosidase, extracted from hog small intestine. Černý and Staněk, ${ }^{8}$ have suggested in the review on 1,6-anhydroaldohexoses about the usefulness of the compounds for chemical modification of sugars. Little work, however, has been done about reducing disaccharide series.

From these stand points and in order to extend the studies on thiosugars, the authors have now synthesized 1,6-anhydro-6-thio- $\beta$-cellobiose (6-thiocellobiosan) (XIII) starting from

1) Part XV: S. Ishiguro, M: Sakata, M. Haga, and S. Tejima, Chem. Pharm. Bull. (Tokyo), 17, 2571 (1969).

2) Location: Tanabe-dori, Mizuho-ku', Nagoya.

3) G.G.S. Dutton and K.N. Slessor, Can. J. Chem., 44, 1069 (1966).

4) R.T. Sleeter and H.B. Sinclair, J. Org. Chem., 35, 3804 (1970).

5) H. Arita, M. Isemura, T. Ikenaka, and Y. Matsushima, Bull. Chem. Soc. Japan, 43, 818 (1970); H. Arita and Y. Matsushima, J. Biochem. (Tokyo), 70, 795 (1971).

6) S. Tejima, Carbohyd. Res., 20, 123 (1971).

7) M. Sato and I. Yamashina, J. Biochem. (Tokyo), 70, 683 (1971).

8) M. Černý and J. Staněk, "Fortschritte der Chemischen Forschung," Band 14, Heft 4, Springer-Verlag, Heidelberg, 1970, pp. 526-555. 
cellobiosan hexaacetate (II) along with several cellobiose derivatives having sulfur atom in the reducing moiety. In the course of the preparation, valuable information on the reactivities of cellobiose derivatives has been acquired, and the preparation of new compounds is now reported in full detail.

Cellobiosan hexaacetate (II) was first prepared by Hudson, et al., ${ }^{9)}$ and later, the compound has been used by Lindberg and Selleby ${ }^{10)}$ as a starting material in the synthesis of cellobiouronic acid. The authors also selected II as a major starting material of the present work. The original procedure, however, requires a prolonged heating, forty-eight hours, with large volumes of aqueous alkali which consume times in the step of evaporation. Therefore, in the first place, a facile synthesis of II was designed.

According to the paper on the alkaline degradation of phenyl glycosides, reported by the same authors ${ }^{11)}$ mentioned above, 1,6-anhydro ring formation was affected by the substituents in phenyl. Namely, in aryl $\beta$-D-glucopyranosides, $o$ - or $p$-nitrophenyl cleaved faster than phenyl, to form 1,6-anhydro ring. On the contrary, $o$-cresyl was slower than phenyl which required, with the same alkalinity, more than two-fold time of heating to complete the reaction. Among several aryl $\beta$-cellobiosides tested, 0 -chlorophenyl hepta-O-acetyl- $\beta$-cellobioside (I) was the most suitable one for a facile synthesis of II. In this case, cellobiosan formation goes to completion by reflux of a mixture of I with about six-fold aqueous alkali for less than four hours. The progress of the reaction, disappearance of I and formation of cellobiosan, is able to check by thin-layer chromatography (TLC), and the resulted cellobiosan is separated as fully acetate (II) in a yield of $66 \%$ which offers much saving in time and simplifies the procedure.

Zemplén degradation of II, followed by treatment of the product with mercuric acetate in order to replace the chlorine atom by an acetoxy group, afforded $1,2,3,2^{\prime}, 3^{\prime}, 4^{\prime}, 6^{\prime}$-heptaO-acetyl- $\beta$-cellobiose (III) in a yield of $45 \%$. The procedure was a slight modification of that used in the preparation of the corresponding lactose series reported by Tejima. ${ }^{6}$ Previously, Lindberg, et al. ${ }^{12}$ ) have reported on Zemplén degradation of II in the presence of a small amount of acetic acid with a prolonged reaction time, which does not improve the yield. The physical constants of the product prepared by us were in good agreement with those of Lindberg, et al.

On methanesulfonation or $p$-toluenesulfonation in the usual way, III yielded $1,2,3,2^{\prime}, 3^{\prime},-$ $4^{\prime}, 6^{\prime}$-hepta-O-acetyl-6-O-methylsulfonyl- $\beta$-cellobiose (IV) or $1,2,3,2^{\prime}, 3^{\prime}, 4^{\prime}, 6^{\prime}$-hepta-O-acetyl6 -O-p-tolylsulfonyl- $\beta$-cellobiose $(\mathrm{V})$, respectively. Treatment of IV or V with sodium iodide in boiling acetonitrile caused replacement of the sulfonyloxy group by iodine, and crystalline $1,2,3,2^{\prime}, 3^{\prime}, 4^{\prime}, 6^{\prime}$-hepta-O-acetyl-6-deoxy-6-iodo- $\beta$-cellobiose (VI) was obtained in a yield of $71 \%$; this confirmed that the sulfonyl group in IV and V was located on the primary alcohol group. Further proof of this structure was obtained by alkaline degradation of IV and V. Treatment of IV and V with sodium methoxide in methanol, followed by acetylation, afforded II in a good yield. From analogy with levoglycosan formation which has been reported by Tejima and co-workers, ${ }^{6,13)}$ this result presumably supports the structures assigned. to IV and $\mathrm{V}$, in which an acetoxy group ( $\beta$-configuration) is attached to $\mathrm{C}_{1}$, and a sulfonyloxy group at $\mathrm{C}_{6}$.

Treatment of IV with a brominating agent afforded the corresponding syrupy bromide. In this preparation, a slight modification of the procedure used by Scheurer and Smith ${ }^{14}$, for the synthesis of peracetylated glycosyl bromide was employed. By warming of the bro-

9) E.M. Montgomery, N.K. Richtmyer, and C.S. Hudson, J. Am. Chem. Soc., 65, 1848 (1943).

10) B. Lindberg and L. Selleby, Acta Chem. Scand., 14, 1051 (1960).

11) E.M. Montgomery, N.K. Richtmyer, and C.S. Hudson, J. Am. Chem. Soc., 65, 3 (1943).

12) I. Johnssson, B. Lindberg, and O. Theander, Acta Chem. Scand., 17, 2019 (1963).

13) M. Akagi, S. Tejima, and M. Haga, Chem. Pharm. Bull. (Tokyo), 10, 905, 1039 (1962).

14) P.G. Scheurer and F. Smith, J.Am. Chem. Soc., 76, 3224 (1954). 
mide with excess potassium ethylxanthate in ethanol for five minutes; to effect dissolution, two spots were detectable by TLC, and both of which were positive test on irradiation with ultraviolet (UV) lamp. The two spots were also detectable, contaminated with the unreacted bromide, even if equimolar potassium ethylxanthate had been reacted under the same condition. From the reaction mixture, two crystalline compounds were isolated by silica gel column chromatography. Namely, from the faster moving effluent, crystals (VII), mp 143$145^{\circ}$ and $[\alpha]_{\mathrm{D}}^{17}-4^{\circ}$, were separated in a yield of $32 \%$. The infrared (IR) spectrum revealed the absence of methylsulfonyl and the elemental analyses were in good agreement with that of diethylxanthate, $\mathrm{C}_{30} \mathrm{H}_{42} \mathrm{O}_{17} \mathrm{~S}_{4}$. The nuclear magnetic resonance (NMR) $\left(\mathrm{CDCl}_{3}\right)$ spectrum showed the presence of six acetyl groups at 7.94, 7.80, and $7.84 \tau$ each as singlet. Two methyl groups at 8.58 and 8.50 each as triplet, and two methylene groups at 5.25 as quartet revealed the presence of two ethylxanthates. The strong UV absorption at $276 \mathrm{~m} \mu,(\varepsilon)$ : 21000 , was almost two-fold of that of cellobiosyl monoethylxanthate. Therefore, VII was assigned to 1,6 -dithio-6-ethoxydithiocarbonyl-2,3,2, $, 3^{\prime}, 4^{\prime}, 6^{\prime}$-hexa-O-acetyl- $\beta$-cellobiosyl ethylxanthate. Further proof of this structure was obtained by alkaline degradation of

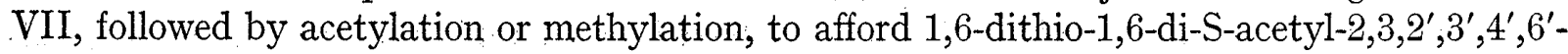

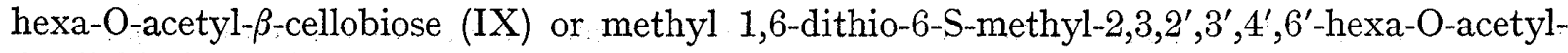
$\beta$-cellobioside $(\mathrm{X})$. The elemental analyses, IR, and NMR data of IX and X were in good agreement with those of the assigned structures; in NMR spectrum of $\mathrm{X}$; however, two thiomethyls overlapped on the six acetyl groups, therefore could not assign independently.

From the latter effluent of the chromatography which was freed from VII, another crystals (VIII), mp $181-182^{\circ},[\alpha]_{\mathrm{D}}^{15}+4^{\circ}$, were separated in a yield of $24 \%$. The IR spectrum revealed the presence of methylsulfonyl at $1165 \mathrm{~cm}^{-1}$. The elemental analyses were in good agreement with that of cellobiosyl monoxanthate, $\mathrm{C}_{28} \mathrm{H}_{40} \mathrm{O}_{19} \mathrm{~S}_{3}$. The UV absorption at $274 \mathrm{~m} \mu,(\varepsilon): 13000$, indicated the presence of monoethylxanthate. Therefore, VIII was assigned to $2,3,2^{\prime}, 3^{\prime}, 4^{\prime}, 6^{\prime}$-hexa-O-acetyl-6-O-methylsulfonyl- $\beta$-cellobiosyl ethylxanthate.

In determination of the values of absorbances (UV) in VII and VIII, hepta-O-acetyl$\beta$-cellobiosyl ethylxanthate (XI) was required as a reference compound. The product, mp $188-189^{\circ},[\alpha]_{\mathrm{D}}^{20}-4.9^{\circ}$, was synthesized in a yield of $83 \%$ starting from hepta-O-acetyl- $\alpha-$ cellobiosyl bromide and potassium ethylxanthate followed by the usual way.

Treatment of compound VIII with sodium methoxide in methanol, followed by acetylation, gave $2,3,2^{\prime}, 3^{\prime}, 4^{\prime}, 6^{\prime}$-hexa-O-acetyl-1,6-anhydro-6-thio- $\beta$-cellobiose $(6$-thiocellobiosan hexaacetate) (XII). mp $150-151^{\circ},[\alpha]_{\mathrm{D}}^{20}-46^{\circ}$, in a yield of $67 \%$. In NMR spectrum showed the presence of six acetyl groups at 7.88 and 7.81 each as singlet. The elemental analyses were in good agreement with that of the assigned structure. Deacetylation of XII in the usual way gave 1,6-anhydro-6-thio- $\beta$-cellobiose (6-thiocellobiosan) (XIII) in a yield of $68 \%$; it was a hygroscopic, amorphous powder, $[\alpha]_{\mathrm{D}}^{15}-59.7^{\circ}$, and was not reducing to boiling Fehling solution. The compound is the fifth "thiolevoglycosan," the thioanalog of 1,6-anhydroglycosan. ${ }^{6,15)}$

Acetolysis of XII with $1 \%$ sulfuric acid as the catalyst permitted opening of the 1,6 anhydro-6-thio ring without cleavage of the disaccharide linkage. The specific rotation changed rapidly from minus to plus in the progress of the reaction, and the mixture assumed

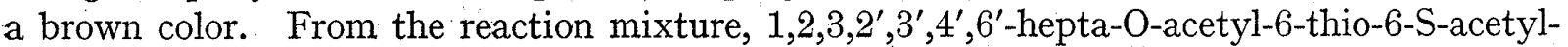
$\alpha$-cellobiose (XIV), mp 248-249,$[\alpha]_{D}^{16}+52.5^{\circ}$, was separated in a yield of $36 \%$. The NMR spectrum showed the presence of one thioacetyl at 7.60 as singlet, and the elemental analyses were in good agreement of the assigned structure. It has been well-known that 1,6-anhydro ring in sugars is subjected to acetolysis, to afford fully acetylated $\alpha$-acetate. Namely, according to the paper reported by Hudson, et al. ${ }^{9)}$ lactosan hexaacetate was converted in a

15) M. Akagi, S. Tejima, and M. Haga, Chem. Pharm. Bull. (Tokyo), 11, 58 (1963); R.L. Whistler and P.A. Seib, Carbohyd. Res., 2, 93 (1966); T. Maki and S. Tejima, Chem. Pharm. Bull. (Tokyo), 15, 1367 (1967). 
yield of $83 \%$ to octaacetyl- $\alpha$-lactose without rupture of the disaccharide union. Recently, Hardegger and Schüep ${ }^{16}$ have synthesized several D-glucose derivatives having sulfur atom, at $\mathrm{C}_{2}$ starting from 1,6-anhydro- $\beta$-D-glucose, via cleavage of the epoxide, followed by acetolysis in the last step. However, no paper has been done on that of the thio analogue. Therefore, it is interesting to notice that, although the yield was not so satisfactory, $36 \%$, the thio analogue cleaved similarly with oxygen analogue, to afford 6 -thioacetyl $\alpha$-acetate (XIV).

Moreover, it is also interesting to notice that the methylsulfonyl in $\dot{C}_{6}$ in $2,3,2^{\prime}, 3^{\prime}, 4^{\prime}, 6^{\prime}-$ hexa-O-acetyl- $\alpha$-cellobiosyl bromide was easily substituted with potassium ethylxanthate under very mild condition, to afford acetylated diethylxanthate (VII) as described in the preparation of VII and VIII. The result presumably suggests, in analogy with the anomalous high reactivity of secondary mesyl in thiosugars which has been reported in the preceding paper of this series, the participation of sulfur atom at $\mathrm{C}_{\mathbf{1}}$. However, the detailed reaction mechanism is now under investigation.
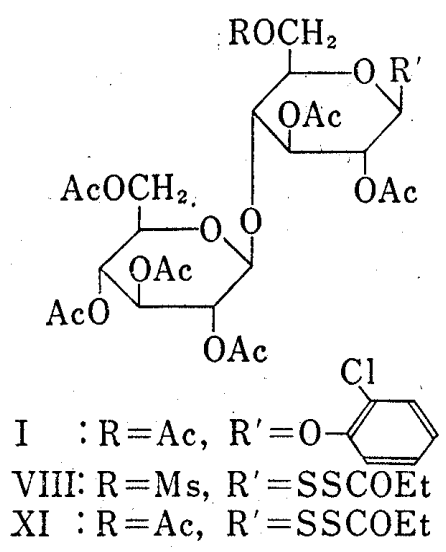

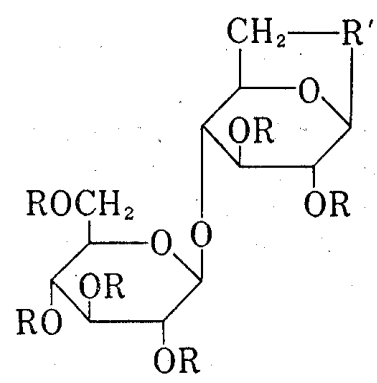

II $: R=A c, R^{\prime}=0$ $\mathrm{XII}: \mathrm{R}=\mathrm{Ac}, \mathrm{R}^{\prime}=\mathrm{S}$ $\mathrm{XIII}: \mathrm{R}=\mathrm{H}, \mathrm{R}^{\prime}=\mathrm{S}$

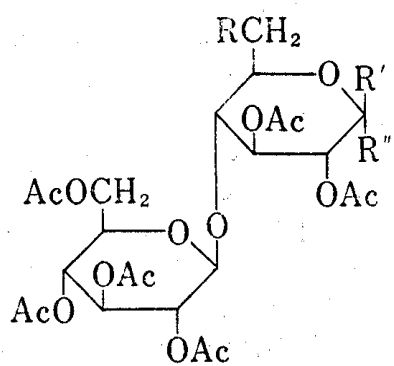

III $: R=O H, \quad R^{\prime}=O A c, R^{\prime \prime}=H$
IV $: R=O M s, R^{\prime}=O A c, R^{\prime \prime}=H$
V $: R=O T s, R^{\prime}=O A c, R^{\prime \prime}=H$
VI $: R=I,, R^{\prime}=O A c, R^{\prime \prime}=H$
VII $: R=R^{\prime}=S S C O E t, R^{\prime \prime}=H$
IX $: R=R^{\prime}=S A c, \quad R^{\prime \prime}=H$
$X \quad: R=R^{\prime}=S M e, \quad R^{\prime \prime}=H$
XIV $: R=S A c, R^{\prime}=H, R^{\prime \prime}=O A c$

\section{Experimental}

Melting points were determined on a Yanagimoto micro $\mathrm{mp}$ apparatus and uncorrected. Solutions were evaporated in a rotary evaporator at $<40^{\circ}$ under diminished pressure. Optical rotations were measured with a Yanagimoto Model OR-10 polarimeter in a $0.5 \mathrm{dm}$ tube. IR spectra were recorded with a Jasco Model IR-S spectrophotometer. NMR spectra were recorded at $60 \mathrm{MHz}$ with a Jeol Model JNMMH-60 spectrometer. Tetramethylsilane was used as the internal standard in $\mathrm{CDCl}_{3}$. Chemical shifts are given on the $\tau$ scale. TLC on Silica Gel GF ${ }_{254}$ (E. Merck, Darmstadt, Germany) activated at $110^{\circ}$ was performed with solvent systems (A) 6:1 (v/v) $\mathrm{CHCl}_{3}$-acetone, (B) $2: 1$ ether-benzene, and (C) $2: 170 \%$ isoPrOH-AcOEt. Detection was effected with $\mathrm{H}_{2} \mathrm{SO}_{4}$ or irradiating with UV lamp. Column chromatography was performed on a column of Wakogel C-200 (Wako Pure Chemical Industries, Ltd., Osaka) as the adsorbent, with $1 \mathrm{~g}$ of the mixture to be separated per $20 \mathrm{~g}$ of adsorbent.

Cellobiosan Hexaacetate (II) -0 -Chlorophenyl hepta-O-acetyl $\beta$-cellobioside (I), mp 201-202 ${ }^{\circ},[\alpha]_{\mathrm{D}}^{18}$ $-44.2^{\circ}\left(c=1.71, \mathrm{CHCl}_{3}\right)$ was synthesized according to the method described by Dea. $\left.{ }^{17}\right) \mathrm{A}$ mixture of I $(35 \mathrm{~g})$ with $3 \mathrm{~N} \mathrm{KOH}(200 \mathrm{ml})$ was refluxed for $3.5 \mathrm{hr}$; the mixture was completely freed of I by TLC. The solution was made neutral at $0^{\circ}$ with $4 \mathrm{~N} \mathrm{H}_{2} \mathrm{SO}_{4}$ and concentrated. The distillation was interrupted thrice so that precipitated salts could be removed by filtration. To the completely dried syrup, obtained by repeated azeotropic distillation with $\mathrm{EtOH}$, were added $\mathrm{Ac}_{2} \mathrm{O}(180 \mathrm{ml})$ and anhyd. AcONa $(18 \mathrm{~g})$. The mixture was heated for $1 \mathrm{hr}$ on a boiling steam bath, and then poured into ice-water and kept overnight. The mixture was extracted with $\mathrm{CH}_{2} \mathrm{Cl}_{2}(4 \times 40 \mathrm{ml})$. The extracts were combined, washed successively with saturated aq. $\mathrm{NaHCO}_{3}$ and $\mathrm{H}_{2} \mathrm{O}$, dried $\left(\mathrm{CaCl}_{2}\right)$, treated with carbon, and evaporated to dryness to afford

16) E. Hardegger and W. Schüep, Helv. Chim. Acta, 53, 951 (1970).

17) I.C.M. Dea, Carbohyd. Res., 12, 297 (1970). 
a brown syrup which crystallized from EtOH. The crystals were collected by filtration, and recrystallized from EtOH. The product $(18 \mathrm{~g}, 66 \%)$ had $\mathrm{mp} 142-143^{\circ}$ and $[\alpha]_{\mathrm{D}}^{20}-54.2^{\circ}\left(c=1.25, \mathrm{CHCl}_{3}\right)$ (lit.9) $\mathrm{mp}$. $145-146^{\circ},[\alpha]_{\mathrm{D}}^{20}-54.4^{\circ}\left(c=2, \mathrm{CHCl}_{3}\right)$.

$1,2,3,2^{\prime}, 3^{\prime}, 4^{\prime}, 6^{\prime}$-Hepta-0-acetyl- $\beta$-cellobiose (III) - To a chilled solution of II (15 g) in dry $\mathrm{CHCl}_{3}$ $(200 \mathrm{ml})$ and $\mathrm{EtOH}(3 \mathrm{ml})$ was added $\mathrm{TiCl}_{4}(15 \mathrm{ml})$. The mixture, protected from moisture, was warmed gently on an oil bath, whereupon vigorous evolution of $\mathrm{HCl}$ ensued; this ceased after about $30 \mathrm{~min}$. The mixture was then boiled under reflux for $4.5 \mathrm{hr}$ and cooled. The yellow, supernatant liquor and the brown, gummy precipitate were poured into ice-water, traces being transferred with the aid of small amounts of $\mathrm{CHCl}_{3}$ and ice-water. The $\mathrm{CHCl}_{3}$ layer was separated, washed with ice-water, dried $\left(\mathrm{CaCl}_{2}\right)$, and evaporated to dryness to afford crystalline $2,3,2^{\prime}, 3^{\prime}, 4^{\prime}, 6^{\prime}$-hexa-O-acetyl- $\alpha$-cellobiosyl chloride. Without further purification, the residue was dissolved in a solution of mercuric acetate $(15 \mathrm{~g})$ in $\mathrm{AcOH}(150 \mathrm{ml})$, and the solution was kept overnight at room temperature, poured into ice-water, and the mixture extracted with: $\mathrm{CH}_{2} \mathrm{Cl}_{2}(3 \times 40 \mathrm{ml})$. The extracts were combined, washed successively with saturated aq. $\mathrm{NaHCO}_{3}$ : and $\mathrm{H}_{2} \mathrm{O}$, dried $\left(\mathrm{CaCl}_{2}\right)$, and evaporated to dryness to afford a syrup which crystallized from EtOH. The crystals were collected by filtration which contaminated with a trace of II and unknown by-products, as shown by TLC (solvent A). Several recrystallization from EtOH gave pure III, homogeneous by TLC. The product $(7.5 \mathrm{~g}, 45.3 \%)$ showed $\mathrm{mp} 207-208^{\circ}$, $[\alpha]_{\mathrm{D}}^{16}-23.5^{\circ}\left(c=1.28, \mathrm{CHCl}_{3}\right)\left(\right.$ lit. ${ }^{12)} \mathrm{mp} 202-203^{\circ}$, $[\alpha]_{0}^{20,}$ $-22^{\circ}\left(c=8, \mathrm{CHCl}_{3}\right)$.

$1,2,3,2^{\prime}, 3^{\prime}, 4^{\prime}, 6^{\prime}$-Hepta-0-acetyl-6-0-methylsulfonyl- $\beta$-cellobiose (IV)-Compound III $(4 \mathrm{~g})$ was added to a solution of $\mathrm{MsCl}(3 \mathrm{~g})$ in pyridine $(20 \mathrm{ml})$ at $-10^{\circ}$. After it had been stirred for $1 \mathrm{hr}$, the mixture was, kept overnight at $5^{\circ}$, poured into ice-water, and the mixture extracted with $\mathrm{CH}_{2} \mathrm{Cl}_{2}(3 \times 30 \mathrm{ml})$. The combined organic layers were washed successively with $3 \mathrm{~N}_{2} \mathrm{SO}_{4}$, aq. $\mathrm{NaHCO}_{3}$ and $\mathrm{H}_{2} \mathrm{O}$, dried, and evaporated to dryness to give a syrup which crystallized on adding EtOH. The crystals were collected by filtration. and recrystallized from EtOH to give pure IV $(4 \mathrm{~g}, 89 \%), \mathrm{mp} 198-199^{\circ},[\alpha]_{\mathrm{D}}^{20}-20.5^{\circ}\left(c=1, \mathrm{CHCl}_{3}\right)$. NMR $\left(\mathrm{CDCl}_{3}\right) \tau: 7.92\left(21 \mathrm{H}, \mathrm{s}, 7 \mathrm{COCH}_{3}\right), 6.90\left(3 \mathrm{H}, \mathrm{s}, \mathrm{OSO}_{2} \mathrm{CH}_{3}\right)$. Anal. Calcd. for $\mathrm{C}_{27} \mathrm{H}_{38} \mathrm{O}_{20} \mathrm{~S}: \mathrm{C}, 45.37 ; \mathrm{H}, 5.35$. Found: $\mathrm{C}, 45.16 ; \mathrm{H}, 5.37$.

$1,2,3,2^{\prime}, 3^{\prime}, 4^{\prime}, 6^{\prime}$-Hepta-0-acetyl-6-0-p-tolylsulfonyl- $\beta$-cellobiose $(\mathrm{V})$-Compound III $(2 \mathrm{~g})$ was added to a solution of $\mathrm{TsCl}_{\mathrm{s}}(3 \mathrm{~g})$ in pyridine $(5 \mathrm{ml})$ at $-10^{\circ}$. The mixture was processed as described for the preparation of IV to give pure V $(2 \mathrm{~g}, 81 \%), \mathrm{mp} 186-188^{\circ},[\alpha]_{0}^{20}-12.1^{\circ}\left(c=1.2, \mathrm{CHCl}_{3}\right)$. Anal. Calcd. for $\mathrm{C}_{33} \mathrm{H}_{40^{-}}$. $\mathrm{O}_{20} \mathrm{~S}: \mathrm{C}, 50.25 ; \mathrm{H}, 5.11$. Found: $\mathrm{C}, 49.96 ; \mathrm{H}, 5.23$.

$1,2,3,2^{\prime}, 3^{\prime}, 4^{\prime}, 6^{\prime}$-Hepta-0-acetyl-6-deoxy-6-iodo- $\beta$-cellobiose (VI)—_A mixture of $\mathrm{V}(200 \mathrm{mg})$, NaI (150 $\mathrm{mg}$ ) and acetonitrile $(5 \mathrm{ml})$ in a sealed tube was heated at $100^{\circ}$ for $2 \mathrm{hr}$. Sodium $p$-tolylsulfonate soon began: to precipitate. The suspension was filtered, and the filtrate was evaporated to dryness. The residue was: triturated with ice-water, to afford a solid which was collected by filtration. The air-dried powder was: recrystallized from EtOH, to give pure VI (150 mg, $71 \%), \mathrm{mp} 214-215^{\circ},[\alpha]_{\mathrm{D}}^{15}-17.7^{\circ}\left(c=1.02, \mathrm{CHCl}_{3}\right)$, Rf 0.55 (solvent B). Anal. Calcd. for $\mathrm{C}_{26} \mathrm{H}_{35} \mathrm{O}_{17} \mathrm{I}: \mathrm{C}, 41.83 ; \mathrm{H}, 4.72$. Found: $\mathrm{C}, 41.71 ; \mathrm{H}, 4.57$.

Compound VI was also obtainable starting from the mesylate IV by a similar procedure.

Cellobiosan Hexaacetate (II) from Sulfonate IV or V-A mixture of the mesylate IV (3 g) with sodium. methoxide in dry $\mathrm{MeOH}$ ( $1 \mathrm{~g}$ of $\mathrm{Na}$ dissolved in $50 \mathrm{ml}$ of dry $\mathrm{MeOH}$ ) was stirred, with exclusion of moisture. for $1 \mathrm{hr}$ at room temperature, and then kept for $15 \mathrm{hr}$, and filtered from the precipitated sodium methanesul-. fonate. The filtrate was made neutral with $\mathrm{AcOH}(1.5 \mathrm{ml})$, and evaporated to dryness. The residue was; acetylated with $\mathrm{Ac}_{2} \mathrm{O}(20 \mathrm{ml})$ and pyridine $(20 \mathrm{ml})$ in the usual way. After recrystallization from EtOH, the product $(1.5 \mathrm{~g}, 62 \%)$ had $\mathrm{mp} 142-143^{\circ},[\alpha]_{\mathrm{D}}^{20}-54^{\circ}\left(c=2.1, \mathrm{CHCl}_{3}\right)$; it was indistinguishable with authentic II (IR and TLC).

Treatment of the tosylate $\mathrm{V}$ by the same procedure also gave II.

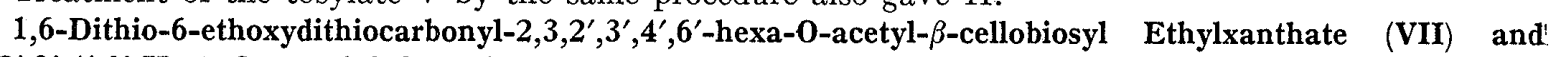
$2,3,2^{\prime}, 3^{\prime}, 4^{\prime}, 6^{\prime}$-Hexa-0-acetyl-6-0-methylsulfonyl- $\beta$-cellobiosyl Ethylxanthate (VIII) - $\mathrm{Br}_{2}(6 \mathrm{ml})$ was added' dropwise under $20^{\circ}$ to a suspension of red $\mathrm{P}(3 \mathrm{~g})$ in glacial AcOH $(30 \mathrm{ml})$ with external cooling. To this: brominating reagent was added finely powdered methanesulfonate IV $(3 \mathrm{~g})$ in one portion, and the suspention was stirred for $30 \mathrm{~min}$. The mixture was kept for $1 \mathrm{hr}$ at room temperatute, $\mathrm{CH}_{2} \mathrm{Cl}_{2}(45 \mathrm{ml})$ was added, and the mixture was poured into ice-water $(600 \mathrm{ml})$, stirred for $30 \mathrm{~min}$ at $0^{\circ}$, and filtered. The organic layer was separated, successively washed with $\mathrm{H}_{2} \mathrm{O}$ and aq. $\mathrm{NaHCO}_{3}$, dried $\left(\mathrm{CaCl}_{2}\right)$, and evaporated, to. give a syrupy $2,3,2^{\prime}, 3^{\prime}, 4^{\prime}, 6^{\prime}$-hexa-O-acetyl-6-O-methylsulfonyl- $\alpha$-cellobiosyl bromide which was used without further purification.

To the syrupy bromide were added potassium ethylxanthate $(3 \mathrm{~g}, 4.6 \mathrm{~mole})$ and EtOH $(60 \mathrm{ml})$. The mixture was warmed for $5 \mathrm{~min}$ at $70^{\circ}$ to effect dissolution, kept for $2 \mathrm{hr}$ at room temperature, and then. poured into ice-water $(200 \mathrm{ml})$ containing $\mathrm{AcOH}(2 \mathrm{ml})$. The mixture was extracted with $\mathrm{CH}_{2} \mathrm{Cl}_{2}(3 \times$ $30 \mathrm{ml}$ ), and the extracts were combined, washed with $\mathrm{H}_{2} \mathrm{O}$, dried $\left(\mathrm{CaCl}_{2}\right)$, and evaporated to a syrup which. crystallized on addition of a small amount of $\mathrm{EtOH}$. The crystals were collected by filtration which showed. two spots, UV positive, $R f 0.5$ and 0.7 , by TLC (solvent A). The crystals were dissolved in $\mathrm{CH}_{2} \mathrm{Cl}_{2}$, and the solution was chromatographed on a column of silica gel. From the forthcoming effluent of $6: 1(\mathrm{v} / \mathrm{v})$ $\mathrm{CHCl}_{3}$-acetone, VII crystallized after removal of the solvent and trituration of the resulting syrup with. EtOH which was collected by filtration and recrystallized from EtOH. The crystals $(1.1 \mathrm{~g}, 32 \%)$ had mp. 
$143-145^{\circ}$ and $[\alpha]_{\mathrm{D}}^{17}-4^{\circ}\left(c=1, \mathrm{CHCl}_{3}\right)$. UV $\lambda_{\max }^{\text {dioxane }} \mathrm{m} \mu(\varepsilon): 276(21000) . \quad \mathrm{NMR}\left(\mathrm{CDCl}_{3}\right) \tau: 8.58,8.50(6 \mathrm{H}$, double triplet, $2\left(\mathrm{CH}_{3}-\mathrm{CH}_{2}\right), 7.94,7.90,7.84\left(18 \mathrm{H}, \mathrm{s}, 6 \mathrm{COCH}_{3}\right), 5.25\left(4 \mathrm{H}, \mathrm{q}, 2\left(\mathrm{CH}_{3}-\mathrm{CH}_{2}\right)\right.$. Anal. Calcd. for $\mathrm{C}_{30} \mathrm{H}_{42} \mathrm{O}_{17} \mathrm{~S}_{4}: \mathrm{C}, 44.88 ; \mathrm{H}, 5.28$. Found: $\mathrm{C}, 44.61 ; \mathrm{H}, 5.68$.

Another crystals (VIII) were separated from the second effluent of the same solvent. Recrystallization from EtOH gave crystals $(0.8 \mathrm{~g}, 24 \%), \mathrm{mp} 181-182^{\circ}$ and $[\alpha]_{\mathrm{D}}^{15}+4^{\circ}\left(c=1, \mathrm{CHCl}_{3}\right)$. UV $\lambda_{\mathrm{max}}^{\text {dloxane }} \mathrm{m}_{\mu}(\varepsilon): 274$ (13000). IR $v_{\max }^{\text {Nujol }}: 1165 \mathrm{~cm}^{-1}$ (mesyl). Anal. Calcd. for $\mathrm{C}_{28} \mathrm{H}_{40} \mathrm{O}_{19} \mathrm{~S}_{3}: \mathrm{C}, 43.20 ; \mathrm{H}, 5.18$. Found: C, 43.20; H, 5.20 .

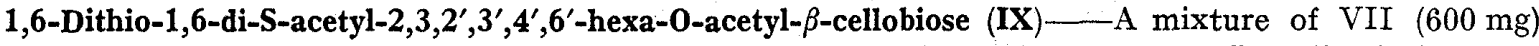
and $1 \mathrm{~N}$ sodium methoxide in $\mathrm{MeOH}(25 \mathrm{ml})$ was stirrred at room temperature to effect dissolution, and then kept for $15 \mathrm{hr}$. The solution was made neutral with $\mathrm{AcOH}$ and evaporated to dryness. The residue was acetylated with $\mathrm{Ac}_{2} \mathrm{O}(6 \mathrm{ml})$ and pyridine $(6 \mathrm{ml})$, and then processed, in the usual way, to give a syrup which was dissolved in $\mathrm{CH}_{2} \mathrm{Cl}_{2}$, and the solution was chromatographed on a column of silica gel using $2: 1$ $(\mathrm{v} / \mathrm{v})$ ether-benzene as the elution solvent. Evaporation of the eluate afforded crystals $(110 \mathrm{mg}, 21 \%)$, $\operatorname{mp} 187-189^{\circ},[\alpha]_{\mathrm{D}}^{15}-7^{\circ}\left(c=1.05, \mathrm{CHCl}_{3}\right)$. IR $v_{\max }^{\text {Nujol }}: 1710 \mathrm{~cm}^{-1}:(\mathrm{SAc}) . \quad \mathrm{NMR}\left(\mathrm{CDCl}_{3}\right): 7.95,7.89(18 \mathrm{H}$, $\left.\mathrm{s}, 6 \mathrm{OCOCH}_{3}\right), 7.60\left(6 \mathrm{H}, \mathrm{s}, 2 \mathrm{SCOCH}_{3}\right)$. Anal. Calcd. for $\mathrm{C}_{28} \mathrm{H}_{38} \mathrm{O}_{17} \mathrm{~S}_{2}: \mathrm{C}, 47.32 ; \mathrm{H}, 5.39$. Found: C, 47.13; $\mathrm{H}, \mathbf{5 . 4 6 .}$

Methyl 1,6-Dithio-6-S-methyl-2,3,2, $3^{\prime}, 4^{\prime}, 6^{\prime}$-hexa-0-acetyl- $\beta$-cellobioside (X)—Alkaline degradation of VII (700 mg) was performed with $1 \mathrm{~N}$ sodium methoxide in $\mathrm{MeOH}(25 \mathrm{ml})$ by stirring for $80 \mathrm{~min}$ at room temperature. To the solution was added $\mathrm{CH}_{3} \mathrm{I}(2 \mathrm{ml})$, and the mixture was stirred for further $10 \mathrm{~min}$. Removal of the solvent afforded a syrup which was acetylated with pyridine $(7 \mathrm{ml})$ and $\mathrm{Ac}_{2} \mathrm{O}(7 \mathrm{ml})$. After standing in a refrigerator overnight, the mixture was poured into ice-water. The precipitated powder so obtained was filtered and air-dried which showed three spots, $R f 0.65$ (main), 0.4 and 0.2 (minors), by TLC (solvent $\mathrm{A}$ ). The product was dissolved in $\mathrm{CH}_{2} \mathrm{Cl}_{2}$, and the solution was chromatographed on a column of silica gel. From the forthcoming effluent of $6: 1(\mathrm{v} / \mathrm{v}) \mathrm{CHCl}_{3}$-acetone, $\mathrm{X}$ crystallized after removal of the solvent. The product $(200 \mathrm{mg}, 35 \%)$ had $\mathrm{mp} 196-198^{\circ}$ and $[\alpha]_{\mathrm{D}}^{15}-11.4^{\circ}\left(c=1.25, \mathrm{CHCl}_{3}\right)$. NMR $\left(\mathrm{CDCl}_{3}\right)$ $\tau: 7.95,7.92,7.85,7.75\left(24 \mathrm{H}, \mathrm{s}, 6 \mathrm{COCH}_{3}+2 \mathrm{SCH}_{3}\right)$. Anal. Calcd for $\mathrm{C}_{26} \mathrm{H}_{38} \mathrm{O}_{15} \mathrm{~S}_{2}: \mathrm{C}, 47.70 ; \mathrm{H}, 5.85$. Found: C, $47.32 ; \mathrm{H}, 5.80$.

Hepta-O-acetyl- $\beta$-cellobiosyl Ethylxanthate (XI)-Hepta-O-acetyl- $\alpha$-cellobiosyl bromide, mp $185^{\circ}$, $[\alpha]_{\mathrm{D}}^{20}+94^{\circ}\left(c=1.07, \mathrm{CHCl}_{3}\right)$ was synthesized in $95 \%$ yield according to the method described by Scheurer and Smith. ${ }^{14)}$

To the bromide $(8 \mathrm{~g})$ were added potassium ethylxanthate $(8 \mathrm{~g})$ and EtOH $(120 \mathrm{ml})$. The mixture was warmed for $10 \mathrm{~min}$ on a steam bath $\left(70-80^{\circ}\right)$ to effect dissolution, stirred for $1 \mathrm{hr}$ at room temperature, and then poured into ice-water $(300 \mathrm{ml})$ containing $\mathrm{AcOH}(5 \mathrm{ml})$. The mixture was extracted with $\mathrm{CH}_{2} \mathrm{Cl}_{2}$ $(3 \times 30 \mathrm{ml})$, and the extracts were combined, washed with $\mathrm{H}_{2} \mathrm{O}$, dried $\left(\mathrm{CaCl}_{2}\right)$, and evaporated to a syrup which crystallized on addition of a small amount of EtOH and scratching of the inside of the flask. The crystals were collected by filtration, and recrystallized from EtOH, to give pure XI (7 $\mathrm{g}, 83 \%)$, mp 188$189^{\circ},[\alpha]_{\mathrm{D}}^{20}-4.9^{\circ}\left(c=1.44, \mathrm{CHCl}_{3}\right)$. UV $\lambda_{\max }^{\text {dloxane }} \mathrm{m} \mu(\varepsilon): 274(10000)$. NMR $\left(\mathrm{CDCl}_{3}\right) \tau: 8.50\left(3 \mathrm{H}, \mathrm{t},-\mathrm{CH}_{2}-\mathrm{CH}_{3}\right)$, 7.95, 7.90, $7.85\left(21 \mathrm{H}, \mathrm{s}, 7 \mathrm{COCH}_{3}\right)$. Anal. Calcd. for $\mathrm{C}_{29} \mathrm{H}_{40} \mathrm{O}_{8} \mathrm{~S}_{2}: \mathrm{C}, 47.02 ; \mathrm{H}, 5.44$. Found: C, 46.89; $\mathrm{H}$, 5.36 .

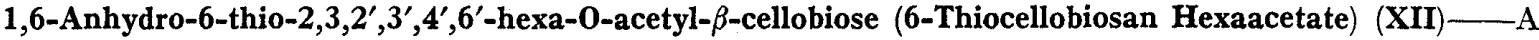
mixture of VIII $(1 \mathrm{~g})$ in dry $\mathrm{MeOH}(30 \mathrm{ml})$ containing $\mathrm{Na}(0.5 \mathrm{~g})$ was stirred for $1 \mathrm{hr}$ at room temperature, and then kept overnight in a refrigerator. The mixture was made neutral with $\mathrm{AcOH}$, and filtered, and the filtrate was evaporated to dryness. The residue was acetylated with $\mathrm{Ac}_{2} \mathrm{O}(6 \mathrm{ml})$ and pyridine $(6 \mathrm{ml})$ for $24 \mathrm{hr}$ at $0^{\circ}$. The mixture was poured into ice-water, and extracted with $\mathrm{CH}_{2} \mathrm{Cl}_{2}$, and the organic layer was processed in the usual way, to afford a syrup which crystallized from $9: 1(\mathrm{v} / \mathrm{v})$ cyclohexane-EtOH in a refrigerator. The product was collected by filtration, and recrystallized from EtOH to give pure needles $(0.5 \mathrm{~g}, 67 \%), \operatorname{mp} 150-151^{\circ},[\alpha]_{\mathrm{D}}^{20}-46^{\circ}\left(c=1, \mathrm{CHCl}_{3}\right)$. TLC: Rf 0.58 (solvent A), 0.3 (solvent B). Anal. Calcd. for $\mathrm{C}_{24} \mathrm{H}_{35} \mathrm{O}_{15} \mathrm{~S}: \mathrm{C}, 48.40 ; \mathrm{H}, 5.38$. Found: $\mathrm{C}, 48.41 ; \mathrm{H}, 5.44$.

1,6-Anhydro-6-thio- $\beta$-cellobiose (6-Thiocellobiosan) (XIII)-CTo a suspension of XII (200 $\mathrm{mg})$ in dry $\mathrm{MeOH}(10 \mathrm{ml})$ was added $1 \mathrm{~N}$ sodium methoxide in $\mathrm{MeOH}(0.1 \mathrm{ml})$. The mixture was stirred, with excluslon of moisture, for $1 \mathrm{hr}$ at room temperature; the complete deacetylation was checked by TLC. Dry Amberlite IR-120 $\left(\mathrm{H}^{+}\right)$resin was added, and the suspension was stirred for $30 \mathrm{~min}$, and then filtered. Evaporation of the filtrate afforded a hygroscopic, amorphous powder $(77 \mathrm{mg}, 68 \%)$. The product, $[\alpha]_{D}^{15}$ $-59.7^{\circ}\left(c=1.54, \mathrm{H}_{2} \mathrm{O}\right)$ was homogeneous by TLC which showed $R f 0.75$ (solvent $\mathrm{C}$ ).

$1,2,3,2^{\prime}, 3^{\prime}, 4^{\prime}, 6^{\prime}$-Hepta-0-acetyl-6-thio-6-S-acetyl- $\alpha$-cellobiose (XIV)-C_-Compound XII (300 mg) was dissolved in the acetolysis mixture $\left(6 \mathrm{ml} ; 1: 70: 30(\mathrm{v} / \mathrm{v}) \mathrm{H}_{2} \mathrm{SO}_{4}-\mathrm{Ac}_{2} \mathrm{O}-\mathrm{AcOH}\right)$. After stirring for $3 \mathrm{hr}$ at room temperature, the solution was poured into ice-water $(200 \mathrm{ml})$. The precipitated powder so obtained was filtered and airdried powder was recrystallized twice from $\mathrm{EtOH}$, to afford pure needles $(120 \mathrm{mg}, 36 \%)$, $\operatorname{mp} 248-249^{\circ},[\alpha]_{\mathrm{D}}^{16}+52.5^{\circ}\left(c=1.04, \mathrm{CHCl}_{3}\right)$. IR $\nu_{\max }^{\text {Nujol }}: 1710 \mathrm{~cm}^{-1}(\mathrm{SAc}) . \quad$ NMR $\left(\mathrm{CDCl}_{3}\right) \tau: 7.96,7.89$, $7.80\left(18 \mathrm{H}, \mathrm{s}, 6 \mathrm{OCOCH}_{3}\right), 7.60\left(3 \mathrm{H}, \mathrm{s}, \mathrm{SCOCH}_{3}\right)$. Anal. Calcd. for $\mathrm{C}_{28} \mathrm{H}_{38} \mathrm{O}_{18} \mathrm{~S}: \mathrm{C}, 48.41 ; \mathrm{H}, 5.51$. Found: $\mathrm{C}, 48.14 ; \mathrm{H}, 5.54$.

Acknowledgement The authors thank Mrs. T. Ban and Mrs. S. Ito for the elemental analyses. 